\title{
Parkinson's disease in the state of Michoacan, evolution, and treatment
}

\author{
Marcela García-Villa ${ }^{1 *}$, Raúl Leal-Cantú2 ${ }^{2}$ Rosa G. Madrigal-Salas², Ildefonso Rodríguez-Leyva ${ }^{3,4}$, \\ Mariana A. Quintana-Díaz', and Conne L. Gonzalez-García ${ }^{6}$ \\ ${ }^{1}$ Clinical Neurology Service, Hospital Star Médica, Morelia, Michoacán; ${ }^{2}$ Neurology Department, Hospital General "Dr. Miguel Silva," Morelia, \\ Michoacan; ${ }^{3}$ Neurology Department, Hospital Central "Dr. Ignacio Morones Prieto", San Luis Potosí; "Medicine School, Universidad Autónoma de \\ San Luis Potosí, San Luis Potosi; ${ }^{5}$ Medicine and Health Scinence School, Tecnológico de Monterrey, Guadalajara, Jalisco; ${ }^{6}$ Clinical Research Unity, \\ Hospital General "Dr. Miguel Silva," Morelia, Michoacán. Mexico
}

\begin{abstract}
Objective: This work is the first registry focused on knowing patients' characteristics with Parkinson's disease (PD), evolution and treatment used in the state of Michoacán. Methods: 68 patients with PD from the neurology consultation of the General Hospital "Dr. Miguel Silva" from October 1, 2019, to December 31, 2019, who fulfilled the UKPDSBB criteria, were studied. Sociodemographic data, disease duration, and severity according to the Unified Parkinson's Disease Rating Scale (MDS-UPDRS) and Hoehn and Yahr Scale were collected. Results: $A$ total of 68 patients were included in the study. Seven of them were eliminated for not meeting the inclusion criteria. Of the 61 evaluated, 31 (50.8\%) were women, the mean age was 68 years ( \pm 9.8$)$ and the age of diagnosis was 61 years $( \pm 12.6)$. The predominant comorbidities were diabetes mellitus (16.4\%), systemic arterial hypertension (44.3\%), and depression (70.5\%). The dominant phenotype was rigid-akinetic, with absence or slight tremor in $50.8 \%$. About $36.1 \%$ had between 5 and 10 years of suffering from the disease. $36.1 \%$ had exposure to pesticides; $31.1 \%$ had a history of head trauma. There were $24.6 \%$ smoking and $31.1 \%$ alcoholism. The drugs most used for motor manifestations were levodopa/carbidopa in $83.6 \%$ and pramipexole in $31.1 \%$. In part I of the MDS-UPDRS scale, the mean score was $9.8 \pm 6.0$; part II 14.37 \pm 9.6 ; part III $21.22 \pm 12.4$ and part IV $3.2 \pm 3.69$. HY, I occupied $37.7 \%$; II 26.2\%; III 23\%; IV 9.8\% and V 3.3\%. Conclusions: In this population, the disease occurred without distinction of gender. The only treatment was pharmacological. Rehabilitation, the support of the psychiatrist and nutritionists, is essential for comprehensive management.
\end{abstract}

Keywords: Parkinson's disease. Mexico. Cross-sectional study.

\section{Enfermedad de Parkinson en el estado de Michoacán, evolución y tratamiento}

\section{Resumen}

Objetivo: Este trabajo es el primer registro enfocado en conocer las características, evolución y tratamiento de los pacientes con enfermedad de Parkinson (EP) utilizados en el estado de Michoacán. Material y métodos: Se estudiaron 68 pacientes con EP de la consulta de neurología del Hospital General "Dr. Miguel Silva" del 1 de octubre de 2019 al 31 de diciembre de 2019, que cumplieran con los criterios de la UKPDSBB. Se recogieron datos sociodemográficos, duración y gravedad de la enfermedad según la Escala Unificada de Calificación de la Enfermedad de Parkinson (MDS-UPDRS) y la

Correspondence:

*Marcela García-Villa

E-mail: margarvi@ hotmail.com
Available online: 03-01-2022

Date of reception: 01-03-2021

Date of acceptance: $31-08-2021$

DOI: 10.24875/RMN.21000018
Rev Mex Neuroci. 2022;23(1):14-21

www.revmexneurociencia.com 2604-6180/ @ 2021 Academia Mexicana de Neurología A.C. Published by Permanyer. This is an open access article under the CC BY-NC-ND license (http://creativecommons.org/licenses/by-nc-nd/4.0/). 
Escala de Hoehn y Yahr. Resultados: Se incluyó a un total de 68 pacientes. Siete de ellos fueron eliminados por no cumplir con los criterios de inclusión. De los 61 evaluados, 31 (50.8\%) eran mujeres, la edad media fue de 68 años \pm 9.8 años y la edad de diagnóstico fue de 61 años \pm 12.6. Las comorbilidades predominantes fueron diabetes mellitus $(16.4 \%)$, hipertensión arterial sistémica (44.3\%) y depresión (70.5\%). El fenotipo dominante fue rígido-acinético, con ausencia o leve temblor en el 50.8\%. El 36.1\% tenía entre 5 y 10 años de padecer la enfermedad. $36.1 \%$ tuvo exposición a plaguicidas y 31.1\% tenía antecedentes de traumatismo craneoencefálico. Los fármacos más utilizados para las manifestaciones motoras fueron levodopa/carbidopa en el 83.6\% y pramipexol en 31.1\%. En la parte I de la escala MDS-UPDRS, la puntuación media fue de $9.8 \pm 6$,0; parte II, $14.37 \pm 9.6$; parte III $21.22 \pm 12.4$ y en la parte IV $3.2 \pm 3.69$. HY, I ocupó 37.5\%; II 26.2\%; III 23\%; IV $9.8 \%$ y $\vee 3.3 \%$. Conclusiones: En esta población la enfermedad se presentó sin distinción de género. El único tratamiento fue farmacológico. La rehabilitación, el apoyo del psiquiatra y nutriología se hacen indispensables para el manejo integral.

Palabras clave: Enfermedad de Parkinson. México. Estudio transversal.

\section{Introduction}

Parkinson's disease (PD) is a complex neurodegenerative adult-onset process and is the second most common proteinopathy after Alzheimer's dementia'.

The British surgeon James Parkinson is acknowledged for publishing the first description of the disease in his "Essay on the Shaking Palsy" in 18172. Three years later that the eponymous was suggested by the French neurologist Jean-Martin Charcot as "La Maladie de Parkinson. ${ }^{3,4 "}$

In the present day, the prevalence and incidence of numerous neurological diseases have increased considerably in recent decades, especially those related to the aging process 5 . PD has been no stranger to this increase, as it is one of the most frequent disorders in neurology consultations ${ }^{6}$.

The etiology of PD is unknown, but it is attributed to a combination of environmental and genetic factors ${ }^{7}$. Dopaminergic denervation of the substantia nigra pars compacta projections to the striatal nucleus leads to an alteration in the basal ganglia's normal physiology ${ }^{8}$. Age is the most consistent risk factor and, as the age of the general population increases, the prevalence of $\mathrm{PD}$ will steadily increase in the future ${ }^{9}$. In fact, neurodegenerative diseases are projected to overtake cancer as the second most common cause of death among the elderly by 2040 and the number of cases with PD to double between 2005 and 20307,10.

The reported frequency of PD varies depending on the diagnostic criteria employed, the population studied, or the epidemiological methods used. The prevalence is estimated to be $0.3 \%$ of the general population and approximately $1 \%$ in those over 60 . The estimated worldwide incidence ranges from 8 to $18 / 100,000$ inhabitants/year ${ }^{11}$. Almost all epidemiological studies have shown that both the incidence and prevalence of $\mathrm{PD}$ are higher in men than in women, suggesting a possible protective effect of estrogens ${ }^{12,13}$. Several environmental factors such as exposure to pesticides or repeated head trauma have been associated with an increased risk, while others such as caffeine, tobacco or alcohol consumption, or taking nonsteroidal anti-inflammatory drugs could be protective factors ${ }^{14,15}$.

Motor disturbances are the main clinical manifestations of PD. Due to the clinical heterogeneity of presentation, attempts have been made to classify the disease into subtypes, such as the tremor dominant and non-tremor dominant groups; the latter referred also as rigid-akinetic phenotype and includes the postural instability and gait disorder (PIGD) subtype ${ }^{16}$. This differentiation could have prognostic implications as the disease course differs between the subtypes and the tremor subtype having the best prognosis ${ }^{17}$.

Non-motor symptoms of PD have gained prominence in recent years because they can precede the classic motor symptoms and are a major determinant of patients' quality of life ${ }^{18}$. The non-motor symptoms involve mood disorders, autonomic dysfunction, sleep disorders, sensory symptoms, and cognitive disturbances ${ }^{19,20}$.

Ultimately, the role of preclinical detection of PD will be determined by the ability to emerge therapies to influence clinical outcomes ${ }^{21}$. Conventional treatment often does not provide adequate motor control; as the patient suffers a progressive lack of efficacy of dopaminergic therapy fluctuations and dyskinesias appear, becoming a complex therapeutic challenge ${ }^{22}$. More than $80 \%$ of subjects with PD after $15-20$ years of evolution present: dementia, freezing of gait, and falls resulting in fractures in up to $35 \%$ of cases $^{22,23}$.

\section{Materials and methods}

This is an observational, descriptive, and cross-sectional study. Patients who fulfilled the UKPDSBB criteria (UK Parkinson's Disease [PD] Society Brain Bank) 
attended at the General Hospital "Dr. Miguel Silva" and at the private neurology consultation of Neurologists belonging to the Michoacán Association of Neuroscience AC, from October 1, 2019, to December 31, 2019 were included in the study. Exclusion criteria were as follows: patients with parkinsonism which did not meet the UKPDSBB criteria, patients using drugs that could cause parkinsonism, patients with vascular parkinsonism, and patients who did not agree to participate in the study. The data collection consisted of sociodemographic variables (gender, age, age at onset, subtype at onset, and antiparkinsonian drug use), disease duration and severity according to the Unified Parkinson's Disease Rating Scale (MDS-UPDRS), and Hoehn and Yahr (HY) scale.

This research protocol was reviewed and approved by the Research Ethics Committee of the General Hospital "Dr. Miguel Silva" of Morelia, Michoacán. All participants provided informed consent for participation.

\section{Statistical analysis}

Descriptive statistics were obtained, using measures of central tendency: mean, mode, median, and range; for quantitative variables; and proportions and percentages for qualitative variables that allowed tables and graphs to be made. The data obtained were collected on a data sheet and processed in the SPSS 23 statistical package.

\section{Results}

During the analyzed period, comprising from October 1, 2019, to December 31, 2019, a total of 68 patients agreed to participate, seven of them were excluded (due to the absence of scales application, the final diagnosis of drug-induced parkinsonism, or erroneous PD diagnosis). Of 61 patients who met the inclusion criteria, $31(50.8 \%)$ were women and the mean age was 68 years \pm 9.8 years. In respect of education, the majority $(42.6 \%)$ had only elementary school education, $4.9 \%$ had no formal education but knew how to read and write their name, $6.6 \%$ were unschooled, while only $1.6 \%$ had a postgraduate degree. Concerning other sociodemographic variables, $70.5 \%$ were married, $23.0 \%$ were widowed, and $6.6 \%$ were unmarried. The majority of this population is active, $34.4 \%$ are housewives, $29.5 \%$ are employed, and the same percentage is unemployed, with only one subject continuing his undergraduate studies.
The mean age of diagnosis of Parkinson's disease was 61 years \pm 12.6 . The age of onset of motor symptoms was questioned; however, the patients did not know it, although $80 \%$ referred from 4 to 8 months before diagnosis. Three patients $(4.9 \%)$ reported a family history of Parkinson's disease. The main comorbidities presented were depression $(70.5 \%)$, systemic arterial hypertension (44.3\%), diabetes mellitus (16.4\%), cancer $(6.6 \%)$, chronic renal insufficiency $(3.3 \%)$, and heart disease (3.3\%). The patients were graded, and the Unified Parkinson's Disease Scale MDS-UPDRS was used to identify the dominant clinical phenotype. They were divided into four phenotypes: (1) tremor-predominant phenotype, (2) rigid-kinetic phenotype with absence or mild tremor, (3) phenotype with instability and gait disorder known as PIGD, and (4) mixed or indeterminate clinical phenotype. The predominant phenotype was rigid-akinetic, with absence or slight tremor in $50.8 \%$. Of the total sample, $36.1 \%$ had been suffering from the disease for 5 to 10 years. With concern of risk factors, 22 patients $(36.1 \%)$ had exposure to pesticides and 19 (31.1\%) had a history of craniocerebral trauma. As of protective factors, 15 patients $(24.6 \%)$ were found to be smokers.

The most commonly used medication for motor manifestations was levodopa/carbidopa in $83.6 \%$, pramipexole in $31.1 \%$, and rasagiline in $14.8 \%$. However, biperiden is not included in the primary treatment of $\mathrm{PD}$, and it was found to be still used in $21.3 \%$. As for treatment for dyskinesias/fluctuations, only $10 \%$ used amantadine. For the treatment of depression and anxiety, $11.5 \%$ used citalopram and $6.6 \%$ used clonazepam. For psychosis, clozapine used $6.6 \%$, and quetiapine used $4.9 \%$. For REM sleep behavior disorder, clonazepam was used in $18 \%$ and melatonin in $6.6 \%$. No drugs to treat orthostatic hypotension were found. Domperidone and sennosides were used with $6.6 \%$ frequency each; $11.5 \%$ took omeprazole for gastritis associated with gastrointestinal problems. The $8.2 \%$ used tamsulosin for genitourinary dysfunction, although it should be noted that this drug was taken for prostate problems, not for voiding problems associated with PD (Table 1).

From evaluating patients with the MDS-UPDRS, we obtained the following results: the mean scores of the non-motor experiences of daily living (part I) were 9.8 \pm 6.0 , of the motor experiences of daily living (part II) were $14.37 \pm 9.6$, of the motor examination (part III) were $21.22 \pm 12.4$, and of motor complications (part IV) were $3.2 \pm 3.69$. When considering the four aspects of the scale, the mean overall score was $48.5 \pm 25.9$. 
Table 1. Most used drugs for motor and non-motor manifestations in PD. Biperiden was used in $21.3 \%$ even though it's outside the basic treatment for PD

\begin{tabular}{|l|l|c|}
\hline Medication & Used for & Percentage \\
\hline $\begin{array}{l}\text { Levodopa/ } \\
\text { carbidopa }\end{array}$ & Motor manifestations & 83.6 \\
\hline Pramipexole & Motor manifestations & 31.1 \\
\hline Biperidene & Motor manifestations & 21.3 \\
\hline Rasagiline & Motor manifestations & 14.8 \\
\hline Amantadine & Dyskinesias/fluctuations & 10 \\
\hline Citalopram & Depression and anxiety & 11.5 \\
\hline Clonazepam & Depression and anxiety & 6.6 \\
\hline Clozapine & Psychosis & 6.6 \\
\hline Ouetiapine & Psychosis & 4.9 \\
\hline Clonazepam & Rem behavioral sleep disorder & 18 \\
\hline Melatonin & Rem behavioral sleep disorder & 6.6 \\
\hline Domperidone & Gastrointestinal dysfunction & 6.6 \\
\hline Sennosides & Gastrointestinal dysfunction & 6.6 \\
\hline Paring & & \\
\hline
\end{tabular}

PD: Parkinson's disease.

Figures 1, 2, 3, and 4 show the percentage of the subscales of the MDS-UPDRS parts I, II, III, and IV, respectively.

According to the Hoehn and Yahr scale, Stage I occupied $37.7 \%$, Stage II $26.2 \%$, Stage III $23 \%$, Stage IV $9.8 \%$, and Stage V 3.3\% (Figure 5).

\section{Discussion}

To the best of our knowledge, this is the first study in the state of Michoacán, Mexico, that evaluates Parkinson's disease's characteristics. Of the 61 patients who participated in the study, $50.8 \%$ were female and $49.2 \%$ were male. The presentation age was 68 years \pm 9.8 years, which is similar to that reported internationally; as for gender, the disease presented equally. However, the literature indicates a predominance in the male gender ${ }^{1,24}$. In comparison with the Mexican PD Registry (ReMePARK), a multicenter cohort study published in 2013 provided the first insight into the motor, non-motor, and genetic determinants of Parkinson's disease, the mean age of the patients was $64.7 \pm$ 12.9 years $^{24}$.

The treatment of symptoms should be adapted to the evolution, phase of the disease, type of symptomatology, and disability. Approximately $80 \%$ of patients respond adequately to levodopa initially. Still, motor symptom control will gradually diminish over the next 2-5 years. Around $50 \%$ of them will develop disabling side effects (motor fluctuations, peak-dose dyskinesias, and dopaminergic dysregulation syndrome $)^{25}$. The DATATOP study proposed that there is no loss of response to levodopa after long-term therapy. However, the deterioration of these patients represents the disease's progression; in general, the effect on tremor, rigidity, and bradykinesia does not change, but other alterations such as speech, postural responses, and gait are increased $^{23,25}$. Patients who have no response to dopaminergic treatment can be benefited from the various pharmacological strategies. Other therapies use subcutaneous perfusion of apomorphine, continuous intestinal perfusion of levodopa/carbidopa, and deep brain stimulation $(\mathrm{DBS})^{26}$. Although those therapies effectively improve motor complications and non-motor aspects of PD, they are different in goals, benefits profiles, and risks. The proper selection for each treatment is a determining for the possibilities of the treatment success ${ }^{26}$. The magnetic resonance imaging-guided by high-intensity focused ultrasound (MRI/ FUS) has led to an interest in lesional procedures for tremor $^{27}$. Functional neurosurgery procedure through MRI/FUS offers a safe and efficient noninvasive therapeutic lesion possibility ${ }^{28}$. The term "advanced therapies" based on experimental cell or gene therapies may generate further confusion in a lay setting, as many PD patients will not be candidates for these therapies $^{29}$. TRANSEURO is a European multicenter open-label study using human fetal dopamine cells and will be completed in $2021^{30}$.

Unfortunately, we do not have therapies such as subcutaneous perfusion of apomorphine, continuous intestinal perfusion of levodopa/carbidopa, or DBS, neither MRI/FUS. To address the question which provides more remarkable improvement: optimal medical therapy or DBS, 225 patients from 7 Veterans Affairs departments, and six university hospitals were studied in a randomized controlled study designed to compare the effects of DBS (STN, $n=60$; or GPi, $n=61$ ) and "best medical therapy" ( $n=134)$ after 6 months of treatment. Patients treated with DBS gained a mean score of $4.6 \mathrm{~h} /$ day without dyskinesia than $0 \mathrm{~h} /$ day for patients receiving best medical therapy $(p<0.001)$. Furthermore, motor function improved by five or more points on the UPDRS motor assessment in $71 \%$ of DBS and $32 \%$ in medical therapy patients ${ }^{31}$. It is expected that health services in our country will have available 


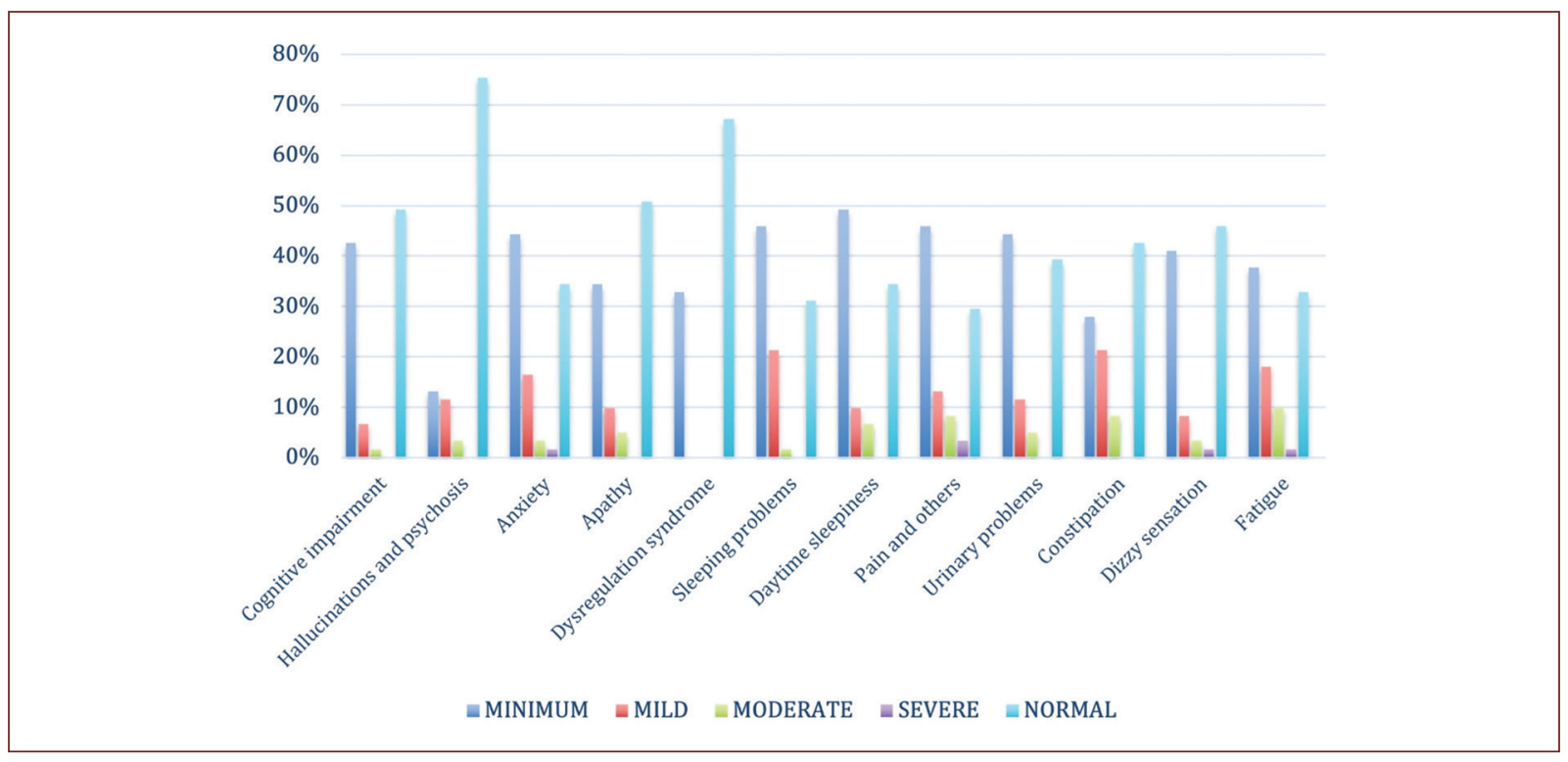

Figure 1. Proportions of non-motor experiences of daily living.

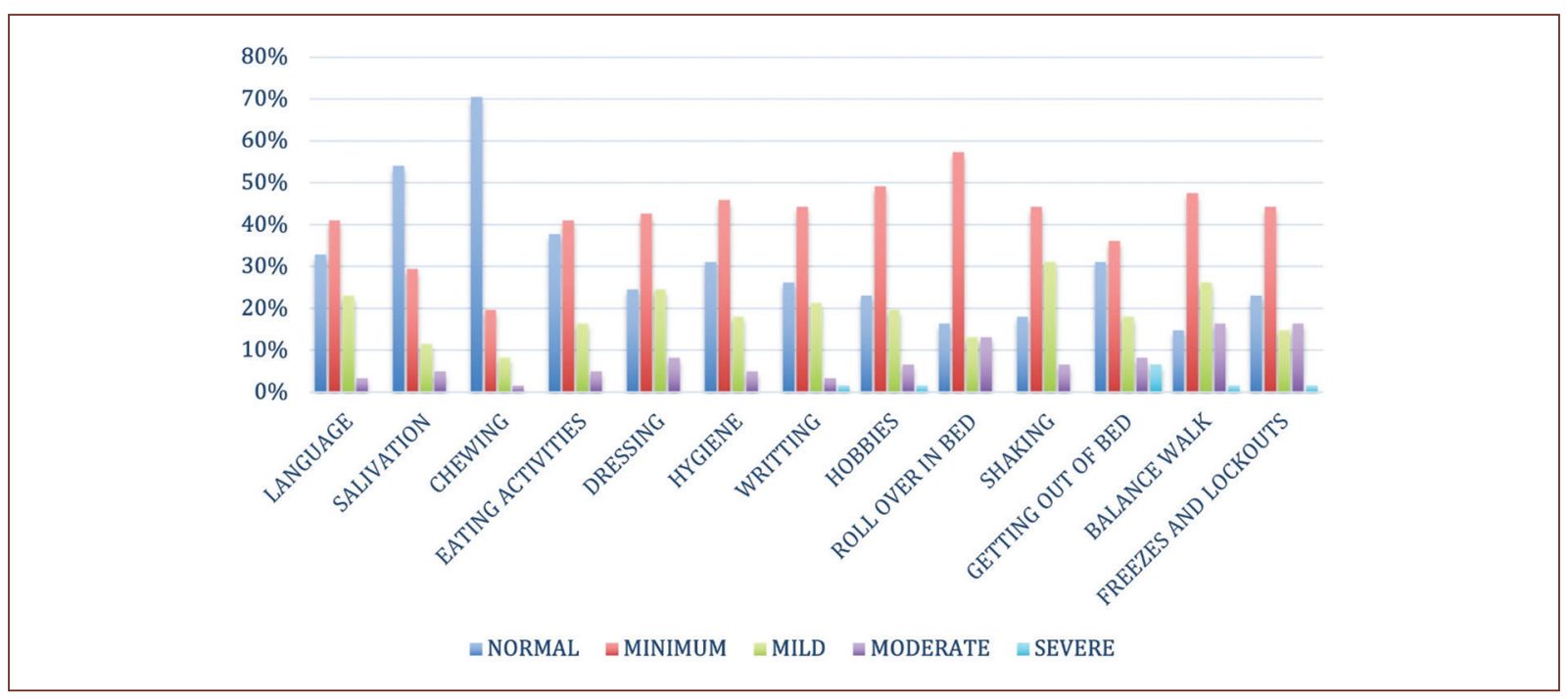

Figure 2. Proportions of motor experiences of daily living.

specific treatment alternatives for patients with PD in the future.

In contrast to what is reported in the literature, it is noteworthy that the predominant phenotype found in our study was rigid-akinetic, with no or mild tremor, probably due to this study's limitations, follow-up time was short.

Chen et al. concluded that there is sufficient evidence to suggest that non-pharmacological therapies (e.g., behavioral-behavioral therapy) are highly effective in treating PD patients' anxiety ${ }^{32}$. In our setting, there are no non-pharmacological therapies, and pharmacological treatments are insufficient to treat anxiety and depression, so the urgency of multidisciplinary and comprehensive work is evident so that the patient with PD can achieve a better quality of life. Similar to Dobkin et al., ${ }^{33}$ most patients with PD suffer from some degree of depression.

Non-motor symptoms may be divided in dysautonomic, neuropsychiatric, sleep, and sensory disorders. Rodriguez-Violante et al. in their study prevalence of non-motor dysfunction among Parkinson's disease 


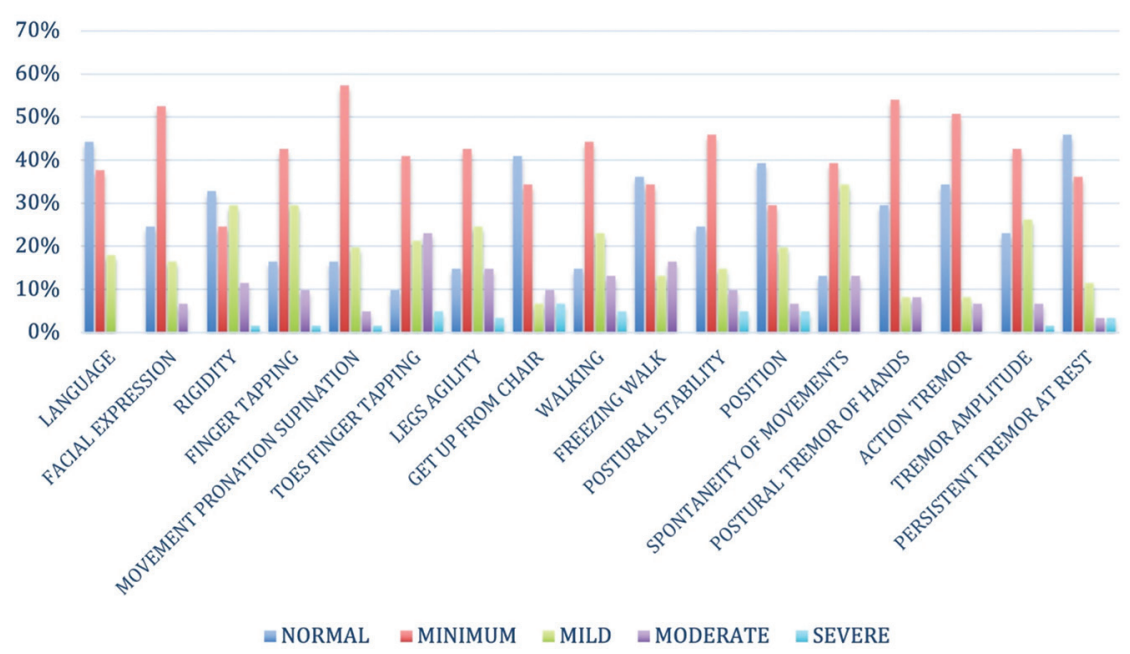

Figure 3. Proportion of motor symptoms.

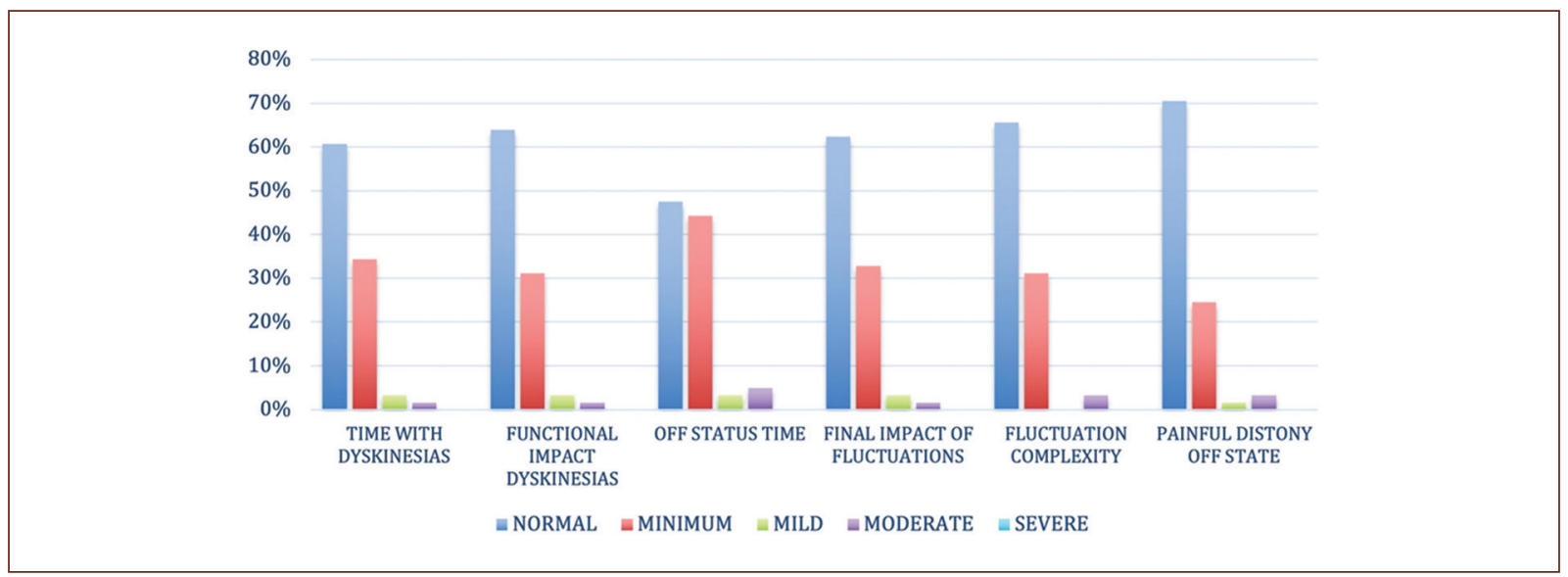

Figure 4. Proportion of motor complications. The time in the off stage and dyskinesias ranked as minimum in $44.3 \%$ and $34.4 \%$, respectively.

patients from a tertiary referral center in Mexico City evaluated the prevalence of these symptoms in a sample of Mexican patients with PD who attended a neurological referral center using the non-motor symptom questionnaire and the non-motor symptom scale, found that the prevalence of non-motor symptoms among Mexican patients with PD is similar to other countries. Mood, cognitive, and perceptual symptoms seem to be more severe in our population ${ }^{34}$. In our study, we found depression in $70.5 \%$ of the patients.

The comorbidities found in patients with PD by Nataraj and Rajput ${ }^{35}$, compared with those found in this study, are approximate. Comparing their results to ours: systemic arterial hypertension in $31.1 \%$ versus $44.3 \%$; diabetes mellitus in $12.9 \%$ versus $16.4 \%$; and non-smokers in $65.5 \%$ versus $75.4 \%$. Smoking may be important as it links nicotine as a protector of dopaminergic neurons since it has been shown to stimulate dopamine release in the striatum and preserve dopaminergic function in experimental models ${ }^{36}$.

Related to the $\mathrm{H}-\mathrm{Y}$ staging, Weintraub et al. reported the stage distribution as follows: $\mathrm{H}-\mathrm{YI}(12.7 \%) ; \mathrm{H}-\mathrm{YII}$ (54.5\%); HY-III (27.6\%); and HY-IV (5.2\%) $)^{37}$. In our study, the result was as follows: Stages I (37.7\%), II $(26.2 \%)$, III $(23 \%)$, IV $(9.8 \%)$, and V $(3.3 \%)$.

The exposure to pesticides found in this study was $36.1 \%$, which corresponds to more than one-third of the population studied. Pesticide exposure has been 


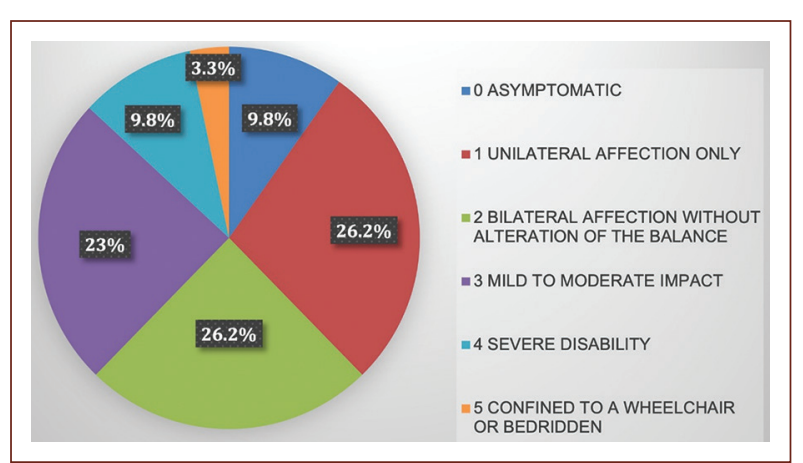

Figure 5. Hoehn and Yahr scale stages.

described to be associated with an increased risk of $\mathrm{PD}$, with an odds ratio ranging from 1.6 to 7 . Based on epidemiological studies supporting an association between pesticide exposure and PD, an animal model of PD pathogenesis has been proposed. Continuous infusion of rotenone into the jugular vein of rats for several weeks produced highly selective degeneration of the nigrostriatal dopaminergic pathway, associated clinically with bradykinesia and rigidity, and pathologically with staining of cytoplasmic fibrillar inclusions for ubiquitin and alpha-synuclein ${ }^{38}$.

Despite the increase in PD, research in Latin American PD patients remains scarce ${ }^{39}$. The growing population growth in Latin America highlights the importance of PD research in this population, and there are some indications that the prevalence of PD in Mexico will double in 20 years, highlighting the importance of PD research studies in more regions of our country ${ }^{40}$.

\section{Conclusions}

Considering that $\mathrm{PD}$ is progressive and degenerative, it is necessary to develop preventive strategies to reduce the impact of complications on patients' quality of life; this would be achieved with interdisciplinary work covering all the aspects needed for a better general condition. The patients' medical insurance does not cover the high costs of pharmacological and non-pharmacological therapies, such as Sistema de Protección Social en Salud, Instituto Mexicano del Seguro Social, or the Instituto de Seguridad y Servicios Sociales de los Trabajadores del Estado, not having a dimension of this problem, hinders the care of this disease in the State of Michoacán.

On the other hand, the increasing growth of $P D$ in Mexico highlights the importance of more PD research studies in our country.

\section{Funding}

This research has not received any specific grant from public, commercial, or non-profit sector agencies.

\section{Conflicts of interest}

The authors declare that they have no conflicts of interest.

\section{Ethical disclosures}

Protection of human and animal subjects. The authors declare that no experiments were performed on humans or animals for this study.

Confidentiality of data. The authors declare that they have followed the protocols of their work center on the publication of patient data.

Right to privacy and informed consent. The authors have obtained the written informed consent of the patients or subjects mentioned in the article. The corresponding author is in possession of this document.

\section{References}

1. Martínez Fernández R, Gasca Salas C, Sánchez-Ferro A, Obeso JA. Parkinson's disease: a review. Rev Med Clin Condes. 2016;27:363-79.

2. Parkinson J. An Essay on the Shaking Palsy. London: Sherwood Neely and Jones; 1817.

3. Goetz CG. Charcot on Parkinson's disease. Mov Disord. 1986;1:27-32.

4. Stern G. Did parkinsonism occur before 1817? J Neurol Neurosurg Psychiatry. 1989;52:11-2.

5. Benito-León J, Moreno S, Romero JP. Epidemiología descriptiva del temblor. In: Gironell A, editor. Temblor. Barcelona: Marge Médica Books; 2011. p. 43-62.

6. Benito-León J. Epidemiología de la enfermedad de parkinson en españa y contextualización mundial. Rev Neurol. 2018;66:125-34.

7. Long A, Lozano A. Parkinson disease. First of two parts. NEJM. 1998;339:1044-53.

8. Obeso JA, Rodriguez-Oroz MC, Benitez-Temino B, Blesa FJ, Guridi J, Marin $C$, et al. Functional organization of the basal ganglia: therapeutic implications for Parkinson's disease. Move Disord. 2008;23:S548-59.

9. Morens D, Davis JW, Grandinetti A, Ross GW, Popper JS, White LR. Epidemiologic observations on Parkinson's disease: incidence and mortality in a prospective study of middle-aged men. Neurology. 1996;46:1044-50.

10. Dorsey ER, Constantinescu R, Thompson JP, Biglan KM, Holloway RG, Kieburtz K, et al. Projected number of people with Parkinson disease in the most populous nations, 2005 through 2030. Neurology. 2007;68: 384-6.

11. De Lau LM, Breteler MM. Epidemiology of Parkinson's disease. Lancet Neurol. 2006;5:525-35.

12. Picillo M, Nicoletti A, Fetoni V, Garavaglia B, Barone P, Pellecchia MT La relevancia del género en la Enfermedad de Parkinson: una revisión. Acta Neurol Colombiana. 2017;264:1583-607.

13. Schrag A, Ben-Shlomo Y, Brown R, Marsden CD, Quinn N. Young-onset Parkinson's disease revisited-clinical features, natural history, and mortality. Move Disord. 1998;13:885-94.

14. Ascherio A, Schwarzschild MA. The epidemiology of Parkinson's disease: risk factors and prevention. Lancet Neurol. 2016;15:1257-72.

15. Noyce AJ, Bestwick JP, Silveira-Moriyama L, Hawkes CH, Giovannoni G, Lees AJ, et al. Meta-analysis of early non motor features and risk factors for Parkinson disease. Ann Neurol. 2012;72:893-901.

16. Marras C, Lang A. Parkinson's disease subtypes: lost in translation? J Neurol Neurosurg Psychiatry. 2013;84:409-15.

17. Alvarado-Franco NL, Olguín-Ramírez L, Eisinger RS, Ramírez-Zamora A, Cervantes-Arriaga A, Rodríguez-Violante M, et al. Análisis de subtipos motores en la enfermedad de Parkinson: registro Mexicano de enfermedad de Parkinson (ReMePARK). Rev Mex Neurosci. 2018;19:3-8. 


\section{García-Villa et al.: Parkinson’s disease in Michoacán, Mexico}

18. Rodríguez-Violante M, Cervantes-Arriaga A, Morales-Briceño H, Neri-Nani G, Estrada-Bellmann I, Millán-Cepeda MR, et al. Estudio multicéntrico de evaluación de la sintomatología no motora través de la Escala unificada de la enfermedad de Parkinson de la sociedad de trastornos de movimiento (MDS-UPDRS). Rev Mex Neuroci. 2014;15:201-6.

19. Rodriguez-Orozco MC, Jahanshahi M, Krack P, Litvan I, Macias R, Bezard E, et al. Initial clinical manifestations of Parkinson's disease: features and pathophysiological mechanisms. Lancet Neurol. 2009;8:1128-39.

20. Chaudhuri KR, Odin P, Antonini A, Martinez-Martin P. Parkinson's disease: the non-motor issues. Parkinsonism Relat Disord. 2011;17:717-23.

21. Bonnet AM, Jutras MF, Czernecki V, Corvol JC, Vidailhet M. Nonmoto symptoms in Parkinson's disease in 2012: relevant clinical aspects. Parkinson Dis 2012;2012:198316.

22. Ahlskog JE, Muenter MD. Frequency of levodopa-related dyskinesias and motor fluctuations as stimated the cumulative literature. Mov Disord. 2001;16:448-58.

23. Kulisevsky J, Luquin MR, Arbeloc JA, Burguerad F, Carrilloe A, Castro F et al. Enfermedad de Parkinson avanzada. Características clínicas tratamiento (parte I). Neurología. 2013;28:503-21.

24. Cervantes-Arriaga A, Rodríguez-Violante M, López-Ruíz M, Estrada-BeIlmann I, Zuñiga-Ramírez C, Otero-Cerdeira, et al. Caracterización de la enfermedad de Parkinson en México: estudio ReMe PARK. Gac Med Mex. 2013;149:497-501.

25. Kulisevsky J, Luquin MR, Arbeloc JA, Burguerad F, Carrilloe A, Castro F, et al. Enfermedad de Parkinson avanzada. Características clínicas y tratamiento (parte II) Neurología. 2013;28:558-83.

26. Martínez-Martin P, Reddy P, Katzenschlager R, Antonini A, Todorova A Odin $\mathrm{P}$, et al. Euroinf: a multicenter comparative observational study of apomorphine and levodopa infusion in Parkinson's disease. Mov Disord. 2015;30:510-6.

27. Mossa S, Martínez-Fernández R, Elias WJ, Del Alamo M, Eisenberg HM Fishman PS. The role of high-intensity focused Ultrasaund as a syntomatic treatment for Parkinson's disease. Mov Disord. 2019;34:1243-51.

28. Gallay MN, Moser D, Federau C, Jeanmonod D. Anatomical and tchnical reappraisal of the pallidothalamic tractotomy with the incisionless transcranial MR-guided focused Ultrasaund. A technical note. Front Surg. 2019;6:2.

29. Guía diagnóstica y terapéutica de la Sociedad Española de Neurología Guía oficial de las recomendaciones clínicas en la Enfermedad de Parkinson. Netherlands: Elsevier; 2019.
30. Barker RA. Designing stem-cell-base dopamine cell replacement trials for Parkinson's disease. Nat Med. 2019;25:1045-53.

31. Weaver FM, Follett K, Stern M, Hur K, Harris C, Marks W Jr., et al. Bilateral deep brain stimulation vs best medical therapy for patients with advanced Parkinson disease: a randomized controlled trial. JAMA. 2009;301:63-73.

32. Chen C, Chen W, Cloyd J, Coles L, Low W, Sanders L, et al. Treatment of anxiety in Parkinson's disease: a systematic literature review. Thirty second annual symposium on etiology, pathogenesis, and treatment of Parkinson disease and other movement disorders. Mov Disord. 2019;34:1-19.

33. Dobkin RD, Gara MA, Rodriguez K, Menza M. Telephone-administered cognitive behavioral therapy for depression in Parkinson's disease: a randomized controlled trial. Thirty second annual symposium on etiology, pathogenesis, and treatment of parkinson disease and other movement disorders. Mov Disord. 2019:34:243-53.

34. Rodríguez-Violante M, Cervantes-Arriaga A, Villar-Velarde A, Corona T. Prevalence of non-motor dysfunction among Parkinson's disease patients from a tertiary referral center in Mexico city. Clin Neurol Neurosurg. 2010;112:883-5

35. Nataraj A, Rajput AH. Parkinson's disease, stroke, and related epidemiology. Mov Disord. 2005;20:1476-80.

36. Jankovic J, Tan EK. Parkinson's disease: etiopathogenesis and treatment. J Neurol Neurosurg Psychiatry. 2020;91:1-14.

37. Weintraub D, Rodriguez-Blazquez C, Schrag A, Rizos A, Chaudhuri KR Martinez-Martin P. Non-motor symptoms burden grading in Parkinson disease with the movement disorders society-non-motor rating scale (MDS-NMS): 1645. Mov Disord. 2019;34:S670.

38. Sherer TB, Betarbet R, Testa CM, Boo Seo B, Richardson JR, Kim JH, et al. Mechanism of toxicity in rotenone models of Parkinson's disease. J Neurosci. 2003;23:10756-64.

39. Trapp S, MacKenzie J, Gonzalez-Arredondo S, Rodriguez-Agudelo Y, Arango-Lasprilla JC. Mediating role of caregiver burden among family caregivers of patients with Parkinson's disease in Mexico. Int J Psychiatry Med. 2019;54:203-16.

40. Smith ER, Perrin PB, Tyler CM, Lageman SK, Villaseñor T. Cross-cultural differences in Parkinson's disease caregiving and burden between the United States and Mexico. Brain Behav. 2020;10:e01753. 